\title{
Impact of coronavirus pandemic on the Indian education sector: perspectives of teachers on online teaching and assessments
}

\author{
Amit Joshi and Muddu Vinay \\ ICFAI Business School, ICFAI University, Dehradun, India, and \\ Preeti Bhaskar \\ University of Technology and Applied Sciences, Ibra College of Technology, Ibra, \\ Oman and ICFAI Business School, ICFAI University, Dehradun, India
}

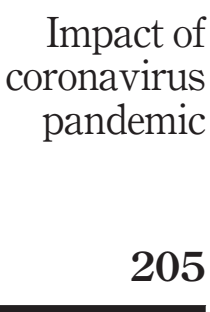

Received 16 June 2020 Revised 24 August 2020 Accepted 26 August 2020

\begin{abstract}
Purpose - In India, the COVID-19 outbreak has been declared an epidemic in all its states and union territories. To combat COVID-19, lockdown was imposed on March 25, 2020 which has adversely affected the education system in the country. It has changed the traditional education system to the educational technologies (EdTechs) model, where teaching and assessments are conducted online. This paper aims to identify the barriers faced by teachers during online teaching and assessment in different home environment settings in India.
\end{abstract}

Design/methodology/approach - Interpretative phenomenological analysis (IPA) of qualitative research methodology has been used in this research. The study was conducted among the teachers working in the government and private universities of Uttarakhand, India. Semi-structured in-depth interviews were conducted among 19 teachers to collect data regarding the barriers faced by them during online teaching and assessment. ATLAS.ti, version 8 was used to analyze the interview data.

Findings - The findings revealed four categories of barriers that are faced by teachers during online teaching and assessments. Under home environment settings, a lack of basic facilities, external distraction and family interruption during teaching and conducting assessments were major issues reported. Institutional support barriers such as the budget for purchasing advanced technologies, a lack of training, a lack of technical support and a lack of clarity and direction were also reported. Teachers also faced technical difficulties. The difficulties were grouped under a lack of technical support, it included a lack of technical infrastructure, limited awareness of online teaching platforms and security concerns. Teachers' personal problems including a lack of technical knowledge, negative attitude, course integration with technology and a lack of motivation are identified as the fourth category to damper their engagement in online teaching and assessments.

Practical implications - The findings of the study can be helpful to the regulatory authorities and employers of higher education institutions who are planning to adopt online teaching as a regular activity in the future. The insights gained from the findings can help them to revisit their existing policy frameworks by designing new strategies and technical structures to assist their teachers in successfully embracing the EdTech to deal with any crisis in the future.

Originality/value - Many authors have conducted research to address the problems faced by students related to online teaching and learning during COVID-19 in India. To the best of the authors' knowledge, this is the first study that addresses the challenges faced by teachers during the online teaching and assessment in the home environment settings by using qualitative analysis (IPA) techniques. The current study replenishes the gap by contributing to the literature of online teaching and assessment under the home environment settings during the pandemic situation.

Keywords HEIs, Coronavirus, COVID-19, Pandemic, Teachers' perspectives

Paper type Research paper

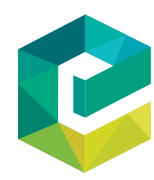

Interactive Technology and Smart Education Vol. 18 No. 2, 2021 pp. $205-226$ pp. 205-226
c Emerald Publishing Limited 1741-5659 DOI 10.1108/ITSE-06-2020-0087 
ITSE

18,2

206

\section{Introduction}

COVID-19, an infectious virus, spread all over the world and adversely affected all facets of the economy. This economic earthquake reached into an astonishing array of many sectors, mutilating them to a great extent. It is estimated that the impact of COVID-19 on the Indian economy during 2020 may reach nearly 8.8tn Indian rupees (Keelery, 2020). The pandemic had incurred an enormous loss to the economy and had a staggering impact on global education. According to UNESCO, 63 million teachers were affected in 165 countries. A total of 1.3 billion learners around the world were not able to attend school or university and approximately 32,07,13,810 learners are affected in India alone (UNESCO, 2020). The Director of the Division of Policies and Lifelong Learning Systems also highlighted the concern that prolonged closure of schools may have major implications on teaching, learning, assessments and credentials. The disruption of teaching and examination has delayed student progression and resulted in a broader socio-economic impact.

In India, the government has announced the lockdown and closure of educational institutions as a logical solution to enforce social distancing within communities. To support their decision Ministry of Human Resource Development in their press release (March 21, 2020) shared various free digital e-learning platforms such as the National Programme on Technology Enhanced Learning, Study Web for Active Young Expiring Minds (SWAYAM), e-Pathshala, DIKSHA portal, SWAYAM Prabha, National Repository of Open Educational, etc. for students so that they may capitalize and continue their learning during lockdown (MHRD, 2020a). The ministry also issued an advisory for HEIs to continue teaching through online mode and requested teachers to teach from home. COVID-19 changed the traditional teaching model to the educational technology (EdTech) model where teachers and students were exposed to new innovative educational methodologies.

Respecting the decision of the government, many higher education institutions (HEIs) started to put their efforts to use technology in support of remote learning, distance education and online learning during the COVID-19 pandemic. Renowned HEIs such as the Institute of Technology, Indian Institutes of Management, Jawaharlal Nehru University, Symbiosis International University, Netaji Subhas University of Technology, IGNOU, Jamia Millia Islamia, ICFAI University and Delhi University offer online classes to their students. However, it is worth mentioning that many HEIs in India are not well equipped with institutionally supported technologies such as Moodle, Blackboard (teaching app), Microsoft Teams and Zoom; however, they made it obligatory for teachers to use open-source online teaching platforms such as WhatsApp, YouTube, Skype and Google hangout to deliver online sessions. Online teaching is stirring at an untested and unprecedented scale and student online assessments are also being conducted with many uncertainties.

It is pertinent that online teaching cannot be successful without the involvement of teachers, as they are the frontline workers of any educational institution. Few studies have addressed the barriers of online teaching in various developed countries such as Germany, Luxembourg (Stoffregen), Japan (Sutherland), FL (Shea), but very limited studies have been conducted on developing countries (Stoffregen et al., 2016; Sutherland, 2014; Shea, 2007). Online teaching is a relatively new concept in developing countries such as India. COVID-19 epidemic has made it mandatory for the teachers of developing countries to use online platforms for teaching and assessment to support the education sector. The teachers need to adapt the technology for the successful execution of online teaching and assessments.

In India, online teaching is not very popular. Most of the teachers were not well trained to teach and conduct assessments online. Because of lockdown, with no choice, teachers started to teach and conduct assessments from their homes. They faced challenges such as a lack of technical infrastructure, namely, a laptop, internet and microphones in their home to teach 
or conduct assessments online. There is no direct technical support that can be offered to teachers in case of any technical difficulty during the online lecture delivery or online assessment. They face distractions because of the frequent visit of family members during online lecture delivery and assessments. Many universities are still using the open-source platform for online teaching which raises questions on the assessment quality and confidentially. This also raises the concern on the quality of student's assessment that may also get compromised because of the teacher's lack of information on the assessment pattern and online assessment platforms.

Online teaching and assessment at home environment setting has different challenges from online teaching and conducting assessment in the university environment. The university environment has a conducive environment where all the facilities are available at ease. This research aims to identify those barriers that are faced by the teachers during online teaching and assessment in the home environment setting in the Indian context. The findings of the study can be helpful to the regulatory authorities and employers of HEIs who are planning to adopt online teaching and assessment as a regular activity in the future.

\section{Review of literature}

The COVID-19 pandemic landed the education system in jeopardy. The challenge thus imposed had to be accepted by the educational institutes to take advantage of asynchronous learning, which works best in digital formats. Online teaching is very different from traditional learning, the shift from conventional pedagogy in higher education to the online mechanism required by teachers to veer their pedagogy. Adapting technology for online teaching within a short span of time was the major challenge for Indian teachers. They were also required to conduct the assessments online, which further escalated their problem. In this viewpoint, Punit and Qz.com (2020) reported that online classes amid lockdown have been an awful experience for teachers. A survey conducted by QS I•GAUGE found that India's technological infrastructure has not achieved a state of quality to ensure the sound delivery of online classes to students (QS-ERA, 2020) Mishra (2020) has also raised the concern for the digital divide and infrastructural dimensions for teaching through online education platforms in India

Recently, many authors have conducted the research to address the problems related to online teaching and learning during COVID 19, but most of the studies have addressed the problem faced by students; ignoring the problems faced by teachers. Only a few authors have addressed the challenges faced by teachers in online teaching and learning. Like, in the study conducted by Gratz and Looney (2020) explored faculty members' willingness to teach online and their resistance to change in Los Angeles where teachers reported they lack skills of teaching online, a lack of time for online course preparation and their subject or course does not suit online teaching. Similarly, Arora and Srinivasan (2020) reported network issues, a lack of training, a lack of awareness, a lack of interest, less attendance, a lack of personal touch and a lack of interaction as major challenges faced by teachers in the online teaching-learning process. Moreover, Kaup et al. (2020) stated challenges related to technology, training and student engagement in sustaining academics during the COVID-19 pandemic. Teachers are not having sufficient infrastructure such as configured laptops, internet and microphones to efficiently impart education. Many teachers face connectivity issues, system failure, bandwidth issues, etc. while conducting online sessions, and because of a lack of technical assistance, they are unable to resolve problems. In agreement, Verma et al. (2020) pointed out that many institutions did not have trained teachers who can work remotely through online platforms and face a struggle to accept the transition. The HEIs instructed their teachers to conduct the classes from their homes without clear instructions 
ITSE

18,2 and directions. They expected old aged teachers who are not technically sound to do online teaching (Sharma, 2020). Teachers also found it difficult to manage the students in remote teaching. Many times students deliberately create indiscipline by playing music, making noise, posting bad comments through fake users, eating and playing games in different windows (Punit and Qz.com, 2020). Teaching in the home environment setting was reported as exhausting and demotivating experience by the teachers.

Previous literature has identified "technology adoption" barriers in online teaching. Buabeng-Andoh (2012) has commonly assumed that teacher-level, school-level and systemlevel barriers discourage teachers to use technology during the teaching process. Lloyd et al. (2012) found institutional barriers, interpersonal barriers, training, technology barriers and cost/benefit analysis barriers perceived for online teaching in south-eastern institutions in the USA. Moreover, Haber and Mills (2008) pointed out that a lack of training, size of the institutions and complexity of the programs were perceived barriers by faculty concerning effective online teaching in Florida. In line, Al-Senaidi et al. (2009) found that a lack of equipment, a lack of institutional support, disbelief of information and communications technology (ICT) benefits, a lack of confidence and a lack of time are the major barriers in adopting technology for teaching and learning in Oman. Additionally, Berge and Mrozowski (1999) categorie barriers to online teaching into nine categories such as academic, fiscal, geographic, governance, labour management, legal, student support, technical and cultural. Some faculties have resisted moving online format because of negative attitude, a lack of time, ICT competence, a lack of technological support, computer self-efficacy, a lack of recognition, course content cannot be translated online, which are barriers to online teaching (Prottas et al., 2016; Keengwe et al., 2008 Yuen and Ma,2008; Chen, 2010; Peralta and Costata, 2007). Many institutions do not provide time, support and financial resources to assist in developing quality online courses (Taylor, 2002).

\section{Methodology}

Interpretative phenomenological analysis (IPA) of qualitative research methodology has been used in this research. IPA aims to explore and understand in detail about the person's experience of a particular phenomenon (Alase, 2017; Smith, 2011; Pringle et al., 2011; Smith and Eatough, 2007). Dipboye and Foster (2002) pointed out that IPA helps in understanding the participant's perception and describing it rather than generalizing it on the basis of preexisting theories and concepts. IPA interview was subjective in nature which generates an opportunity for the investigators to understand the perception of the participants which arose from their experience and involvement in a particular phase of an event. IPA provides not only descriptive but also focused upon interpretative of the views and experiences of the respondent (Smith and Osborn, 2008). Smith 1996, (2004) precisely stated that IPA is deployed in situations where the sample size understudy is small and they are required to be analyzed at greater lengths. Many IPA studies have considered the sample size of 1, 4, 9, 15 and more as a respondent (Smith and Osborn, 2008). Many authors have used IPA in their research work across many disciplines concepts such as spiritualty (Agarwal et al., 2020), elearning (Phutela and Dwivedi, 2020), whistleblowing (Chaudhary et al., 2019); Gupta and Chaudhary (2017), research (Saini and Chaudhary, 2019), genderism (Farmer and Byrd, 2015), emotions (Gill, 2015) and health sciences (Peart et al., 2020; Smith, 2011). In this research, IPA is used to understand the barriers faced in online teaching and assessments during the era of COVID-19 where lockdown had made teachers teach and conduct the assessment in their home environment settings. 


\subsection{Sampling}

The study was conducted among the teachers working in the government and private universities of Uttarakhand, India. There is 1 central university; 11 state universities; 3 Deemed universities and 17 private universities in the Uttarakhand region of India. To get diversity from the viewpoint of teachers, we contacted around 27 teachers through email and phone from different types of universities. All the interested participants were asked to give their written consent and submit the statement carrying ethics approval for participation in the study (Creswell, 2013). Finally, 19 teachers showed interest and agreed to participate in the study (four teachers from central university; five teachers from a state university; five teachers from deemed university; and five teachers from private universities) who are engaged in online teaching and assessment during COVID-19. The study population has ten males and nine females with the age group 26-55 years; all of them were having a minimum of five years of teaching experience. Among the 19 participants, 12 were postgraduates and 7 were having a $\mathrm{PhD}$ degree. Utmost care was taken while selecting the participants as they have to justify the objective of the study.

\subsection{Data collection}

Semi-structured in-depth interviews were conducted to collect data from the teachers to gather information about the barriers faced in online teaching and assessment. The openended questions were not having any predetermined limit or boundary. These questions were verified by six experts for its reliability and validity, and the modifications were incorporated as per the given suggestions. The revised drafts were given to six teachers who were not part of the study to confirm the construct validity. Owing to the lockdown condition, in-person interviews were not conducted, alternatively they were interviewed through the phone. All the interviews were recorded in the form of audio clips. During the primary stage, few triggering questions were asked to the teachers: firstly, what are the problems faced by the teachers in online teaching and assessments in the home environment settings? Secondly, what type of support is provided by their universities in online teaching and assessments? The average time duration of the interview was $60 \mathrm{~min}$ and the overall timing of the interviews fluctuated between 40 and $110 \mathrm{~min}$.

\subsection{Data analysis}

Smith and Osborn (2003) and Moustakas (1994) have recommended the following steps for analysing interview data:

(1) Step 1: All interview records (verbatim transcripts) were closely read and terminologies that provided meaningful insights for recognizing themes for identifying barriers in online teaching and assessments in the home environment settings were recorded.

(2) Step 2: The notes were prepared based on the verbatim transcripts and themes emerging were marked upon the transcripts.

(3) Step 3: These emerging themes were identified and were recorded separately to the transcript. These themes were analyzed for associations-checking for differences and similarities between them and then forming clusters for the themes.

(4) Step 4: Similar themes were grouped and the terminology was given that welldefined higher-order argument. A table comprising of ideas and superordinate themes was produced, and this process was followed for all the interviews conducted for the study (Smith and Osborn, 2003; Cassidy et al., 2011). 
ITSE

18,2

This research followed all the steps suggested by Smith and Osborn (2003) and Moustakas (1994) for the analysis of each interview. To confirm the transparency and accuracy of the analysis process, Ryan and Bernard (2000) cutting and sorting techniques were also used to identify the barriers in online teaching and assessments. In this process, both the investigators coded autonomously and validated the process with an internal consistency of $86 \%$. The results were further discussed until an agreement on the themes was mutual. The study was further authenticated and confirmed by supporting outcomes with verbatim excerpts from five teachers who gave more insights on identified themes. Smith (2011) suggested that verbatim excerpts from three to four respondents per theme are sufficient for a sample size bigger than eight. All the data were analyzed through ATLAS.ti, version 8.

\section{Results}

In this section, findings from the analysis of the 19 interviews using IPA are reported. The findings have been grouped under four larger units known as "meaning units" or "themes," i.e. teaching and assessments in home environment settings, technical difficulties faced by teachers in online teaching and assessments, institutional support for online teaching and assessments and personal problems faced by teachers in online teaching and assessments

\subsection{Theme-1: online teaching and assessments in home environment settings}

The various factors that affect online teaching and assessments in home environment settings are a lack of basic facilities, external distraction and interruption from family members

4.1.1 Lack of basic facilities. Teachers require basic facilities such as marker, whiteboard, printers for smooth online teaching. Because of limited facilities at home, teachers are not able to explain and express themselves in a video conference. Even if the platform is supported by the institutes, then also teachers require basic facilities for the smooth delivery of the lecture.

4.1.1.1 Response on online teaching.

- "Many times it is difficult to explain topic without facilities like whiteboard and marker, though Zoom provides inbuilt whiteboard, but it is not very effective" (Respondent-11).

- "To prepare lectures, sufficient books are not available in my home, college library has many options" (Respondent-09).

- "The conventional teaching has all the facilities like board, marker, and printer. In the home environment settings, these are not available, without these facilities my confidence and efficiency reduces as I am not able to express myself in an influential manner" (Respondent-05).

4.1.1.2 Response on online assessments. Teachers prefer to print out the assignment and then evaluate them. Because of limited facilities at home, teachers are not able to do justice with evaluation. The marks are required to be entered in the software, but it opens for a limited period of time, and once submitted it cannot be edited. Teachers believe in rechecking by taking a printout of the evaluation sheet to in the printing of marks and rechecking, to avoid errors.

- "There are lot of online assignments and it's difficult to check them online. I would like to take the printout and evaluate them, but it is not possible because of absence of printer in my home” (Respondent-10). 
- "Since the marks are directly entered in the software, there are chances of errors. I would prefer to print the student's marks and verify them online to avoid errors. I can't do it because I don't have printer" (Respondent-07).

4.1.2 External distraction. Teachers face a lot of external distractions because of noise created by neighbors, pets, vehicles and visitors. Continuity and efficiency get affected during lecture preparation and delivery.

4.1.2.1 Response on online teaching.

- "Continuity of lecture is interrupted by visitors" (Respondent-04).

- "Disturbance in teaching is caused due to barking of my dog" (Respondent-03).

- "My neighbor keeps on playing loud music" (Respondent-12).

4.1.2.2 Response on online assessments. Because of limited space no matter which platform teachers use, the external distraction is evident in their home environment setting which breaks their concentration, and the chances of error increase during assessment and evaluation.

- "For me, evaluation requires concentration which is broken by frequent visits" (Respondent-11).

- "Television, music, machine noise disrupts my concentration and adversely impact evaluation" (Respondent-05).

4.1.3 Family interference. Teachers face a lot of disturbance because of limited space in the house. There is a lot of distraction from children, conversation between family members, family members approaching for personal work, etc. It results in unwelcomed breakages and teaching is hampered.

4.1.3.1 Response on online teaching.

- "My family do not take online classes seriously and keep coming with household work during the session" (Respondent-10).

- "My daughter interrupts during the class; she is too young to understand the online teaching" (Respondent-16).

- "My son makes lot of noise while playing video games" (Respondent-07).

4.1.3.2 Response on online assessments. Under the home environment setting, teachers reported that the family does not understand the gravity of the online assessments. Regular interruption at home breaks the continuity and results in faulty assessments and evaluation.

- "Evaluation requires reading, understanding, evaluating and deducing, but continuous discussion at home breaks the continuity and creates frustration" (Respondent-06).

- "I miss the assessment evaluation deadlines as household work keeps coming up" (Respondent-03).

\subsection{Theme-2: institutional support for online teaching and assessments}

A teacher requires institutional support for successful online teaching and assessment. Institutes can support them by providing institutional-supported technologies, proper training, technical support and clear directions for successful online teaching and assessments. 
ITSE 18,2

4.2.1 Budget for institutional-supported technologies. The institution should spend money on obtaining a license for institutional-supported technologies. Teachers who were having access to Moodle and Google Meet were able to teach online effectively as compared to the open-source users.

4.2.1.1 Response on online teaching.

- "My university has not taken a license for any online platform for teaching, we use open source software like Skype, WhatsApp, Google meet” (Respondent-04).

- "We are asked to teach online but there are no institutional-supported technologies platforms, so we use open source which lacks effectiveness" (Respondent-15).

- "My organization has provided me with Moodle which has facilities to engage the students through discussion forum" (Respondent-05).

- "I did not face any problems in teaching, teaching with Moodle is easy. I have uploaded all lectures and study materials" (Respondent-8).

4.2.1.2 Response on online assessments. Teachers who were using open-sources for assessment reported faced many problems and limitations. Institutionally supported technology made the process easy for teachers as they could do multiple online assignments and evaluations easily.

- "The open-source online platform doesn't have assessment facilities, so I ask students to send assignments on e-mail" (Respondent-1).

- "I have limited options to assess the students. I ask them to submit the assignment on Google drive" (Respondent-18).

- "Some open-source software allows assessment, but ask for payment to download grade reports, so I don't found them worth" (Respondent-7).

- "I conduct assessment on Moodle by giving an online quiz, it automatically evaluates and gives marks immediately" (Respondent-11).

- "I ask students to submit online assignments on Moodle by giving them a timeline for online submission” (Respondent-19).

4.2.2 Lack of training.

4.2.2.1 Response on online teaching. The teacher needs training in conducting online teaching. Teachers were not well equipped and trained in online teaching. Many institutions instructed teachers to teach online without any training on open-source software.

- "I want to teach online by using Zoom, but I don't understand how to use this platform for teaching" (Respondent-19).

- "I am not trained in online teaching. Many times I found difficult to manage the camera, microphone and teaching together on Skype" (Respondent-19).

- "My institute was already using Moodle for in normal teaching, so I didn't found any difficulty in teaching from home" (Respondent-13).

4.2.2.2 Response on online assessments. Teachers were not aware of online assessment platforms for evaluation and were not well equipped and trained to do online assessments, only a few teachers who were already trained on institutionally supported technology found it easy.

- "I have some idea about Edpuzzle free software for the online quiz, but I am not trained with it. I may so error in designing quiz" (Respondent-17). 
- "I am well versed with Moodle, so during the lockdown, I was able to use it for assessment without any problem" (Respondent-2).

\subsubsection{Lack of technical support.}

4.2.3.1 Response on online teaching. Teachers face technical issues such as connectivity and software's, and they require technical support for online teaching, which is not available at home. An institution using institutional-supported technologies had direct technical support. Their technical issues were resolved by the technical department and the teaching was not hindered, however, the same was not true for teaching through open source as there was no direct support and teaching was taking place on trial and error method.

- "Many times I am unable to connect my laptop with ZOOM and I am unable to identify the problem" (Respondent-10).

- "I found taking online classes is a challenge; there are so many technical things to be taken care" (Respondent-3).

- "I am a novice in technology; don't know how to overcome technical failure. Sometimes I get disconnected and then can't get connected again" (Respondent-17).

- "My organization uses the Moodle as the learning management system (LMS) and had made me well acquainted with it, so I can manage the technical issues easily" (Respondent-12).

- "My university technical department staff is always available online to deal with technical difficulty" (Respondent-15).

4.2.3.2 Response on online assessments. Institute using institutional-supported technologies were having many options for the assessments. If teachers face any issues, technical assistance was provided without any time lag, so the sanity of the evaluation was maintained. Though assessments through open sources were not having any direct technical support and faced and teachers found it difficult to evaluate and time-consuming process.

- "Once I was entering the marks, the laptop, it got hanged, when I restarted the laptop all data was lost. I couldn't ask for any help" (Respondent-9).

- "I have faced issues in downloading the assessment file and opening them. Sometimes the file format is not supported. I have to look for technical support as I am not aware how to change it" (Respondent-14).

- "Assessing students on Moodle platform is easy and in case if I face any problem, my institute technical department provided support" (Respondent-18).

\subsubsection{Lack of clarity and direction.}

4.2.4.1 Response on online teaching. Institutions using institutional-supported technologies have communicated the structure and strategy to implement the online classes time-table. On the other hand, institutions not having any licensed platform and dependent on open software, they did not have any clarity about the process to be followed, a lot of confusion prevailed in that case.

- "I have been asked to teach online, but without any information how it is to be done. No clarity was given about the platform to be used for online teaching" (Respondent-1).

- "I was compelled to teach online, but I don't know how to do it. Simply sending notes on e-mail or Whatsapp is also online teaching" (Respondent-15). 
ITSE

18,2

214

- "My program coordinator has not shared any time table neither any details were given. I am not clear what, when, and how should I do the teaching. I keep on sharing YouTube links with my students where lectures recorded by other faculties" (Respondent-18).

- "Program coordinator has shared the time-table for conducting sessions on Zoom We have been conducting sessions accordingly without any confusion" (Respondent-5).

- "We are required to update all details on Moodle so the Program coordinator can check the progress" (Respondent-8).

4.2.4.2 Response on online assessments. Teachers dependent on open-source software lack clarity and direction and no uniform assessment pattern was adopted by the institution. Teachers were doing it as per the convenience without any clear instruction. Institution supported technologies have become a boon during this time of crisis Teachers had clarity and direction from the institution about the type of assessment to be conducted with proper examination schedule.

- "I am asked to evaluate the students but no clarity and direction is given on how it has to be done" (Respondent-2).

- "I was not told which platform to be used for online assessment" (Respondent-4).

- "I don't any have clear instructions on students assessment, whether we have to take the quiz, assignment, case study, etc." (Respondent-16).

- "Since my institute is using Moodle's for internal evaluation, so we are continuing the same for external assessments" (Respondent-11).

- "Clarity in the evaluation mechanism is provided by the program coordinator. The rubrics are already uploaded on Moodle so I did not face any problem in assessment" (Respondent-13).

4.3 Theme-3: technical difficulties faced by teachers in online teaching and assessments Teachers also face technical difficulties such as availability of technical infrastructure, awareness of the online platform; security issues while doing online teaching and conducting assessments.

\subsubsection{Lack of technical infrastructure.}

4.3.1.1 Response on online teaching. Teachers require good technical infrastructure (hardware, software and internet) for the smooth conducting of the online classes. Most of the teachers did not have the latest configured laptops, microphones, cameras and were using the internet from mobile with low bandwidth, faced a lot of internet connectivity issues.

- "I don't have a laptop at home, difficult to take online classes" (Respondent-7).

- "Online classes require good internet connection, updated software, which I don't have so my online classes get suffered" (Respondent-10).

- "My institute provide with Moodle, but it is of little help because of slow net connectivity at my home" (Respondent-8).

- "I am teaching through Google classroom, but connectivity keeps on loosing" (Respondent-19). 
4.3.1.2 Response on online assessments. Technical infrastructure comes out to be an important factor that disrupts evaluation. They found it difficult to conduct an assessment with limited technical infrastructure. Downloading large files was difficult, they had to wait for a long time for downloading, and regular break of connection affected the evaluation. Regular expiring of the evaluation page made them frustrated and adversely affected the assessment and evaluation.

- "To evaluate the students online I require good internet connection, as the process is to be done in continuity, uninterrupted internet is required" (Respondent-4).

- "I was conducting viva online on Skype, suddenly connectivity got slow so I couldn't hear the students answers clearly" (Respondent-9).

- "Regular expiring of evaluation page made me frustrated and adversely affected the assessment and evaluation" (Respondent-12).

- "Though we have access to Moodle for conducting assessment, but I am unable to use it as my laptop does not support Moodle" (Respondent-3).

- "I couldn't download large files from internet because of low-bandwidth" (Respondent-6).

\subsubsection{Online teaching platform.}

4.3.2.1 Response on online teaching. Teachers teaching on institutional-supported technologies were clear about the teaching platform butconfusion persists where the teachers are using open-source software. Teachers were confused as to which online platform they should use to deliver lectures. Similar problems were reported in assessments.

- "Since all good online platforms are expensive, I am using open software Zoom, but it has a restriction of time and number of users" (Respondent-7).

- "I am sharing YouTube link, presentation, teaching notes through e-mail and handle students queries on WhatsApp" (Respondent-9).

- "I am using Google meet, my institute has taken the license so it's easy to teach online" (Respondent-11).

- "I use institutional supported LMS, so I am clear what, how and when to do, no issues" (Respondent-13).

4.3.2.2 Response on online assessments. Problems were reported where open-sources were used for assessments. Because of the availability of many platforms, teachers were confused about the online platform to be used for assessment whereas teachers using institutionalsupported technologies did not face any issues.

- "I am confused about which online platform should I use to assess the students. There are so many ways like assignment on Google drive, viva on WhatsApp, or live presentation on Google hangout” (Respondent-6).

- "I don't have to think about which platform is to be used; it is made available by my organization. I conduct all the assessments on Moodle" (Respondent-2).

\subsubsection{Security concern.}

4.3.3.1 Response on online teaching. Teachers using open sources for online teaching were considerate about security issues. They were not comfortable in teaching. They reported an issue such as virus attacks, leaking of student data and privacy issues. On the other hand, 
ITSE

18,2

teachers using institutional-supported technologies felt secured as those LMSs are protected and secure because of because of licensed version.

- "My organization has asked me to use Zoom which is open-source and has privacy issues" (Respondent-4).

- "Students data can be exposed through open online platforms and can be misused" (Respondent-10).

- 'I don’t feel comfortable to download free software for online teaching. My laptop has a lot of confidential data which may get affected because of virus in free software" (Respondent-12).

- "I am using Google Meet and licensed taken by the university, so I don't find any security issues" (Respondent-13).

4.3.3.2 Response on online assessments. Teachers perceived security issues such as viruses, malware and phishing attacks while conducting assessment in open source online platforms. Student's sincerity in completing the assessment was also the concern for the teachers in both open source and institutional-supported technologies.

- "Open sources have limited options to evaluate, which compromised the quality of assessments and while downloading the assignments, I am concerned about the virus in the files" (Respondent-1).

- "Good online platforms are expensive, so we use open source for giving assessments. Sometimes I found malware also got download while downloading assignment files" (Respondent-4).

- "Students were not sincere in assessment and they tend to cheat or copy from multiple sources and submit as an assignment. Sometimes these files affect my system configurations" (Respondent-14).

- "The assignment submission quality is very poor. While submitting the assignment, students try to misuse and manipulate the open-source platform" (Respondent-16).

- "Since the software is purchased by my institute, evaluation of all students is confidential, no security concerns" (Respondent-19).

\subsection{Theme-4: personal problems faced by teachers in online teaching and assessments}

Teachers face personal problems such as a lack of online teaching knowledge, negative attitude, course integration with technology and a lack of motivation factors were identified for not engaging in online teaching and assessments.

4.4.1 Lack of online teaching knowledge. Teachers were not acquainted with online teaching platforms, they tried the open-source platform but were not confident. They had insufficient knowledge of online teaching, but because of the lockdown, they used open sources for online teaching. Institutes who have institutional-supported technologies, teachers were having good knowledge of online teaching and executed it efficiently.

\subsubsection{Response on online teaching.}

- 'My university asked me to teach online, but I don't have much knowledge about online teaching. I tried Zoom, but I don't know how to connect with students and use the features of Zoom" (Respondent-6). 
- I am not tech-savvy, so I not able to understand how to teach effectively online. I tried to record my lecture video so that I can share it with students on Youtube, but the video quality is very poor" (Respondent-14).

- 'I can't take classes on WhatsApp for every student; it's so difficult and tiring. So I decided to teach through Google meet, but I don't know how to use it and how to enroll students in it" (Respondent-18).

- "I have full knowledge of Moodle because I was using it in the regular teaching" (Respondent-2).

- 'I am comfortable in using Google meet using it and don't face any problem while teaching online" (Respondent-19).

4.4.1.2 Response on online assessments. Teachers were not aware of online assessment platforms, only a few teachers were having good knowledge of online assessment tools. Most of them use the traditional method for assessments such as the submission of assignments on Google forms or drive. On the other hand, teachers dependent on institutional-supported technologies were having good knowledge of the assessment and evaluation.

- "I have never evaluated students using online platforms, so it is very difficult. I tried to open software for designing quiz, but it is so complicated" (Respondent-12).

- "I am not familiar with many ways of evaluation. I am only conducting quiz on Google forms and asking the student to upload assignments" (Respondent-18).

- "I am familiar with the assessment techniques available on Moodle as I have been doing it for some time in the institute" (Respondent-5).

\subsubsection{Negative attitude.}

4.4.2.1 Response on online teaching. Teachers found online teaching inconvenient and a wastage of time. At home environment setting effective teaching does not take place because of a lack of facilitates, comfort zone and resistance to change. They believe in the conventional method of teaching and expressed a negative attitude toward online teaching. Contrary to this, teachers who were using institutional-supported technologies carried a positive attitude, however, they reported issues related to home-environment.

- "I feel that online teaching is just a formality, as no effective teaching takes place" (Respondent-3).

- "I find it difficult to switch roles, as I am in the comfort zone in my house so I don't feel like teaching” (Respondent-7).

- "Because of lack of resources and facilities, online teaching is adversely affected. I don't feel like teaching anymore" (Respondent-9).

- "Students can understand the concepts with already existing material online on various websites, I don't see any importance online lecture delivery for teaching" (Respondent-12).

- "We have been using blackboard as a LMS for teaching some courses online, so it's similar to teaching from home. I don't find much difference and feel the same" (Respondent-2).

4.4.2.2 Response on online assessments. Teachers found online assessment inconvenient and irrelevant. The assignment submitted by the students were copying from the internet 
ITSE

18,2

218

doesn't have much value. Teachers were asked to prepare multiple types of assignments for each group, which was a tiring and time-consuming process. Designing assignments on the software requires a lot of patience and knowledge, which resulted in a negative attitude among the teachers.

- "Assignments are the internal component of the evaluation, but all assignments are copied, the sanity of evaluation is not there" (Respondent-6).

- "It requires a lot of time to frame questions in the format required by the software which is cumbersome and time taken" (Respondent-9).

- "Checking assignment online is very boring, as most of the student copy from the internet. The answer looks similar, so I'm also not very sincere in evaluation" (Respondent-11).

- "My university has asked me to design multiple types of assignment for different groups to avoid cheating, but its tiring and time consuming to make different types of assessment for every groups" (Respondent-13).

\subsubsection{Course integration with technology.}

4.4.3.1 Response on online teaching. Many teachers agreed that every course cannot be taught online such as numerical, experimental and communication subjects. They require practical exposure and queries need to be resolved with face to face discussion. They found it difficult to integrate their subject with technology, which affected online teaching.

- "I teach financial accounting, I am not able to explain online. I need basic facilities" (Respondent-1).

- "Some subjects can be taught online but my subject requires one on one interaction, it is not possible through online teaching" (Respondent-7).

- "Though my subject is mathematics, I tried to use multiple platforms to teach. I share the notes on Moodle and then I took the class on Zoom to solve the student's queries" (Respondent-2).

- "My subject is all about theory, so I share notes on Moodle if students have any query then contact me through a discussion forum. I also provide additional notes and some YouTube link for more clarification” (Respondent-11).

4.4.3.2 Response on online assessments. Teachers using institutional-supported technologies were able to assess and evaluate the numerical and practical subjects but also agreed that it does not give clarity. Many teachers were not aware of how to write equations and symbols in the online files. It created a lot of confusion about the question.

- "My subject is personality development which requires personal interaction and it is not effective in online channel" (Respondent-6).

- "Open software have only multiple choice question ways of evaluation which do not justify Finance or numerical oriented subjects" (Respondent-7).

- "I can't write the equation on Word or excel, I am not trained, but for online assessment, I have to write, which sometimes change the meaning of questions" (Respondent-9).

\subsubsection{Lack of motivation.}

4.4.4.1 Response on online teaching. Teachers were not motivated for online teaching because of many factors such as a lack of interaction, a lack of student engagement, not able 
to ascertain the psychological and emotional needs of the student, unable to reach out to the students, indiscipline and inability to effectively clear student's doubts. Some teachers also reported that online teaching requires more efforts but that hardship is not recognized by the institutions'

- "It seems I am talking to the wall, there is no energy in the session as students are not engaged" (Respondent-1).

- "I have to mute the students or else few may create disturbance as a result, zeal to teach falls" (Respondent-3).

- "I am unable to understand the psychological need of the students because it's hard ascertained their reactions and sometimes unable to clear their doubts" (Respondent-5).

- "Management doesn't recognize my efforts out in online teaching and there is no incentive or reward for hardship" (Respondent-7)

- "My students are well versed with Moodle since I have been using it regularly, they enjoy the flipped classroom and give complete attention" (Respondent-11)

4.4.4.2 Response on online assessments. Teachers were not motivated for online assessment because they feel that the online assignment is not really needed. Even if they put extra effort to deign assignment on opens sources, most of the students did not complete it sincerely. Institutional-supported technologies made teachers task easy and has not affected their motivation.

- "My students are not serious to submit the assignments or participate in tests, which also demotivate me to put extra efforts for designing assessments" (Respondent-1).

- 'I don't have any interest in designing many assignments; I make the exam paper as it is a compulsion from my university" (Respondent-2).

- "The open software I am using does not have any option to show their marks. I can't discuss the students' performance. The system is too mechanized" (Respondent-6).

- "Since we have been using Moodle to evaluate the students and students are aware of that, they know the importance of the learning platform and they participate with full spirit” (Respondent-19).

\section{Discussion}

While teaching in the home environment setting, teachers encountered many problems. The basic amenities for effective teaching and assessment require a whiteboard, marker and printer. Teaching and assessment require discipline and commitment but many indigenous elements such as noise, visitors, music, family interference and household work existed in home environment settings which adversely impacted the quality of teaching and assessments. In the report submitted by Press Trust of India (2020), continuous external distractions because of clamor from the neighborhood or interruption by family members during the lecture made an adverse effect on the continuity of teaching. Thus, online teaching and assessment in home environment settings have an unpropitious negative influence. It can be clearly stated that teachers either using open-source or institutional support technologies, both face strain in teaching and assessments. A proper setup is required which should be free from external distraction and family disturbance, and basic 
ITSE 18,2 facilities should be available for effective teaching and assessments in the home environment setting.

The second prominent factor which evolved during analysis was the role of the institution for supporting online teaching and assessments. There were two types of the platform available for online teaching and assessment, open sources such as Zoom, Skype, YouTube and Duo and institutional-supported technologies such as LMS, Moodle and Google Meet. Some institutions had obtained the license for institutional-supported technologies and were using them even before the COVID-19 pandemic broke. Those teachers who were well trained, availability of technical assistance and clarity in direction and instruction from the institution did not found any difficulty while conducting online classes and assessments. Contrary to this, teachers belonging to Institutes that were dependent on open sources and had not obtained any licensed online teaching application were in a quandary as they did not have much support from their institutions. They were teaching without any training or technical assistance and were not having any clarity and directions from their institution about teaching and assessment. As a result, teachers belonging to those institutions were apprehensive and unsure about online teaching and assessment. It was distinctly observed that teachers using institutional-supported technologies were able to teach and assess better. Thus it can be mentioned that Institution support can make teachers' tasks easy and stress-free. The importance of classroom learning is undeniable and this pandemic proves that all HEIs and teachers are not yet ready to handle online teaching (Mahesh, 2020; Azevedo et al., 2020)

Because of the pandemic situation, HEIs decided to impart education online. Another biggest challenge faced by teachers was the selection of platforms to conduct online teaching and assessment. Some platforms compromised on the security, data issues, virus and phishing attack which detached the teachers from online teaching and assessment. Teachers using institutionalsupported technologies did not face the problem of choice however limitations of technical infrastructure at home environment settings persisted. The nonavailability of hardware devices, software, internet connectivity and power back-up disrupted the online teaching and assessments and left the teachers annoyed. Regular disruptions and discontinuity make the teacher lose their zeal to successfully conduct teaching and assessments. Thus, it can be witnessed that technical difficulties were faced by teachers of both categories (open-sources or institutional-supported technologies). Proper technical infrastructure and technical assistance need to be provided for effective teaching and assessments. Similar findings were reported in the study conducted by Shenoy et al. (2020) that teachers had a lot of disturbance in the minds to adopt technology for online teaching.

Teacher's confronted personal challenges for teaching and assessments. Many of them were not having knowledge of online teaching and assessments, but because of the pressure from their institution, they were forced to do it, which resulted in their negative attitude. Teachers who used institutional-supported technologies had good knowledge but were not motivated to conduct online sessions because it was a tiring and time-consuming activity. They personally faced challenges such as teaching specific courses (numerical and practical) online, addressing students' doubt and designing online assessment. Teachers were not comfortable teaching some courses which involve numerical, experiments and personal interaction. During face-to-face teaching, language factors are mitigated, as teachers use bilingual communication to respond to students' doubts and queries (Mahajan, 2020). Thus, it is evident that personal challenges need to be addressed for effective online teaching and assessments. The teacher needs to be provided motivation by recognizing their efforts through monetary and nonmonetary rewards such as "best online teacher award", extra incentives for their hardship for online classes and assessments, monetary support for buying technical infrastructure and internet facilities. 


\section{Conclusion}

COVID-19 pandemic has ushered the education system into a tech-savvy path. Though it is evident that online classes and assessments cannot substitute conventional mode of teaching but the role of technology and its extensive use in imparting education cannot be neglected. The paper clearly projects the importance of institutional support technologies in online teaching and assessment. To imbibe technology-driven teaching in real or virtual, it is required to have an exclusive department devoted to developing the technological infrastructure of the institution. Training teachers in LMSs and making it mandatory for all educational purposes will put the institute, teachers and students in a separate league. The future of education seems to be technology-driven and India has to equip itself for it, the paper identifies the huge gap that exists between the open-source versus institutionalsupported technologies and its implication in online teaching and assessments. The Ministry of Human Resources and Development, Government of India has recently proposed a draft on National Education Policy (NEP)-2020 where the focus is made on enhancing teaching and learning through online mode. In the NEP-2020, HEIs are directed to dedicate a budget for online EdTechs (such as LMS, Moodle, Microsoft teams, Google Suite and so on). The policy also emphasizes to promote teaching through advanced technological tools such as artificial intelligence, big data, virtual reality, 3D printing and robotics, develop technical infrastructure and support the advanced teaching and learning mechanism (MHRD, 2020c). Though the NEP-2020 draft is pending for its approval, however, HEIs can initiate to transform the educational ecosystem by adopting online-based teaching and learning.

\section{Practical implications}

The findings of the study can be helpful to the regulatory authorities and employers of HEIs who are planning to adopt online teaching and assessment as a regular activity in the near future. The identified barriers can be considered in advance and a roadmap can be designed for smooth execution of online teaching and assessment. For example, in the press release (29 April 2020) by the Ministry of Human Resource Development, in view of COVID-19 and subsequent lockdown, University Grants Commission issued guidelines on examinations and academic calendar (MHRD, 2020b). The insights gained on the barriers faced by the teacher during an online assessment can be considered by HEIs to plan their examination systematically. Once the HEIs get back to the new normal, teachers can be trained to deal with these barriers for the smooth execution of online teaching and assessment.

\section{Suggestion}

Every dark cloud comes with a silver lining, the lockdown has disturbed the education sector but HEIs have an option to start a new curriculum by integrating traditional and online learning. India should establish a good infrastructure for online education following some of the advanced countries. All higher education institutes now are aware of the importance of technology and should take serious measures to conduct technology-driven education through the LMS. This study offers the following suggestion:

\subsection{Higher education institutions' planning}

The education sector in India should realize the importance of technology and take up stringent measures to implement the technology-driven teaching sessions and assessment. HEI needs to revise its existing policy frameworks by designing new strategies and technical structures to assist their teachers for successfully embracing the EdTech for dealing with any crisis in the future. This study advocates that HEIs should use technology 
ITSE 18,2

in all aspects, beginning with attendance, delivery, assignments, examinations, devices, software, internet connectivity and power back-up, evaluations and results.

\subsection{Teachers: self development}

It is evident that the partnership between technology and education is going to stay forever. Based on this study, the teachers will be able to identify the problems they will face while conducting online classes and assessments. They will be able to equip themselves better and can strategise their efforts by enrolling in those courses which provide training for conducting online teaching and assessment. Teachers need to regularly update their technical knowledge. HEIs can also support their teachers by providing training related to technology and education and providing funds for enrolling in courses that focus on online teaching perspectives.

\subsection{Government support}

Nonavailability of technical infrastructure and irregular interrupted internet connectivity all across India is the biggest challenge in front of the HEIs and teachers. A collaboration of government, technology companies and higher education institutes in the mode of public, private companies, higher education institutes partnership can solve the problem of technical infrastructure. Investing in institutional-supported technologies is a costly venture for HEIs, Government financial support will reduce the burden on the institution and motivate them to adopt technology online teaching and assessments.

\subsection{Promoting sustainable development}

HEIs can divide the courses into conventional teaching and online teaching, it will help in inculcating the technology into the classrooms. The development of course-specific online teaching and assessment plans is a gateway for the strategic execution of technology in the classroom. Online teaching and assessment will reduce paper usage and will contribute to environmental sustainability; it will increase digital literacy among teachers and students which will increase their exposure and learning and making them more employable for the digital world-leading thereby contributing to social sustainability. All these efforts will contribute to economic sustainability by reducing unemployment and contributing to economic growth and development. All these activities will also help in achieving the sustainable development goals of India.

\section{Limitation and future scope}

This research has highlighted the teachers' experiences in home environment settings during a COVID-19 lockdown in India. Firstly, because of the newness of the addressed topic and issue, it was difficult to find the related literature in the Indian context. Though, we have tried to include that literature which has affected other countries education system for online teaching and assessment during the pandemic situation. IPA, the qualitative research methodology has been used in this research. These techniques have some limitations such as there is a possibility that participants might have not disclosed their true intentions and rather have responded in a more socially acceptable and desirable way during the interview. Though, we ensured all the steps suggest by Smith and Osborn (2008) have been meticulously followed. In spite of ensuring objectivity in each and every step in the present study, it is a possibility that other researchers' perspectives may vary and they might draw different themes and carve out varied categories and draw different conclusions. Furthermore, the study has been conducted amongst academic staff/professionals from the 
education sector; therefore, the results cannot be generalized to the professionals of other fields. The present study has involved the teachers working in private and government universities of Uttarakhand, India. In the future, a similar kind of study can be replicated and the findings can be extended to large samples in other states or countries. The research can be extended by the triangulation approach using different techniques and methods to get more valid and reliable results.

\section{Impact of coronavirus pandemic}

223

\section{References}

Agarwal, K., Fortune, L., Heintzman, J.C. and Kelly, L.L. (2020), "Spiritual experiences of long-term meditation practitioners diagnosed with breast cancer: an interpretative phenomenological analysis pilot study", Journal of Religion and Health, pp. 1-17.

Alase, A. (2017), "The interpretative phenomenological analysis (IPA): a guide to a good qualitative research approach", International Journal of Education and Literacy Studies, Vol. 5 No. 2, pp. 9-19.

Al-Senaidi, S., Lin, L. and Poirot, J. (2009), "Barriers to adopting technology for teaching and learning in Oman", Computers and Education, Vol. 53 No. 3, pp. 575-590.

Arora, A.K. and Srinivasan, R. (2020), "Impact of pandemic COVID-19 on the teaching-learning process: a study of higher education teachers", Prabandhan: Indian Journal of Management, Vol. 13 No. 4, pp. 43-56.

Azevedo, J.P. Hasan, A. Goldemberg, D. Iqbal, S.A. and Geven, K. (2020), "Simulating the potential impacts of covid-19 school closures on schooling and learning outcomes: a set of global estimates"

Berge, Z.L. and Mrozowski, S.E. (1999), Barriers to Online Teaching in Elementary, Secondary, and Teacher Education, UMBC Faculty Collection.

Buabeng-Andoh, C. (2012), "Factors influencing teachers adoption and integration of information and communication technology into teaching: a review of the literature", International Journal of Education and Development Using ICT, Vol. 8 No. 1.

Cassidy, E., Reynolds, F., Naylor, S. and De Souza, L. (2011), "Using interpretative phenomenological analysis to inform physiotherapy practice: an introduction with reference to the lived experience of cerebellar ataxia", Physiotherapy Theory and Practice, Vol. 27 No. 4, pp. 263-277.

Chaudhary, N.S., Phoolka, S., Sengar, R. and Pande, S. (2019), "Whistleblowing in Indian higher education sector: a qualitative study", International Journal of Learning and Change, Vol. 11 No. 2, pp. 145-168.

Chen, R.J. (2010), “Investigating models for preservice teachers' use of technology to support studentcentered learning", Computers and Education, Vol. 55 No. 1, pp. 32-42.

Dipboye, R.L. and Foster, J.B. (2002), "Multi-level theorizing about perceptions of organizational politics", Research in Multi-Level Issues, Vol. 1 No. 1, pp. 255-270.

Farmer, L.B. and Byrd, R. (2015), "Genderism in the LGBTQQIA community: an interpretative phenomenological analysis", Journal of LGBT Issues in Counseling, Vol. 9 No. 4, pp. 288-310.

Gill, M.J. (2015), "A phenomenology of feeling: examining the experience of emotion in organizations", New Ways of Studying Emotions in Organizations (Research on Emotion in Organizations), Vol. 11, pp. 29-50.

Gratz, E. and Looney, L. (2020), "Faculty resistance to change: an examination of motivators and barriers to teaching online in higher education", International Journal of Online Pedagogy and Course Design (Design, ), Vol. 10 No. 1, pp. 1-14.

Gupta, K.P. and Chaudhary, N.S. (2017), "Prioritizing the factors influencing whistle blowing intentions of teachers in higher education institutes in India", Procedia Computer Science, Vol. 122, pp. 25-32. 
ITSE 18,2

Haber, J. and Mills, M. (2008), "Perceptions of barriers concerning effective online teaching and policies: florida community college faculty”, Community College Journal of Research and Practice, Vol. 32 No. 4-6, pp. 266-283.

Kaup, S., Jain, R., Shivalli, S., Pandey, S. and Kaup, S. (2020), "Sustaining academics during COVID-19 pandemic: the role of remote teaching-learning", Indian Journal of Ophthalmology, Vol. 68 No. 6, p. 1220.

Keelery, S. (2020), "India - estimated economic impact of COVID-19 by sector 2020 | Statista", Statista, available at: www.statista.com/statistics/1107798/india-estimated-economic-impact-of-coronavirusby-sector/ (Accessed 16 June 2020).

Keengwe, J., Onchwari, G. and Wachira, P. (2008), "The use of computer tools to support meaningful learning", AACE Journal, Vol. 16 No. 1, pp. 77-92.

Lloyd, S.A., Byrne, M.M. and McCoy, T.S. (2012), "Faculty-perceived barriers of online education", Journal of Online Learning and Teaching, Vol. 8 No. 1.

Mahajan, S. (2020), "Technological, social, pedagogical issues must be resolved for online teaching [Web log post]", available at: https:/indianexpress.com/article/opinion/columns/india-coronavirus-lockdownonline-education-learning-6383692/

Mahesh, S. (2020), "A need now but no replacement: teachers share concerns about online classes during COVID-19 [Web log post]", available at: www.newindianexpress.com/education/2020/may/06/a-neednow-but-no-replacement-teachers-share-concerns-about-online-classes-during-covid-19-2139605.html

MHRD (2020a), "Students to continue their learning by making full use of the available digital eLearning platforms - Shri Ramesh Pokhriyal 'Nishank', pib.gov.in., available at: https://pib.gov. in/PressReleasePage.aspx?PRID=1607521 (accessed 16 June 2020).

MHRD (2020b), "UGC guidelines on examinations and academic calendar for the universities in view of COVID-19 and subsequent lockdown”, pib.gov.in, available at: https://pib.gov.in/ PressReleasePage.aspx?PRID=1619368 (accessed 16 June 2020).

MHRD (2020c), “National education policy 2020”, In Press Information Bureau, pp. 33-49, available at: https://static.pib.gov.in/WriteReadData/userfiles/NEP_Final_English_0.pdf (accessed 23 August 2020).

Mishra, S.V. (2020), "COVID-19, online teaching, and deepening digital divide in India”, SocArXiv. June 3 .

Moustakas, C. (1994), Phenomenological Research Methods, Sage publications.

Peart, A., Lewis, V., Barton, C. and Russell, G. (2020), "Healthcare professionals providing care coordination to people living with multimorbidity: an interpretative phenomenological analysis", Journal of Clinical Nursing., Vol. 29 Nos 13/14.

Peralta, H. and Costata, F.A. (2007), "Teachers's competence and confidence regarding the use of ICT", Sísifo-Educational Sciences Journal, pp. 75-84.

Phutela, N. and Dwivedi, S. (2020), “A qualitative study of students' perspective on e-learning adoption in India", Journal of Applied Research in Higher Education.

Press Trust of India (2020), "From technological queries to distress calls, teachers struggle with challenges posed by lockdown", NDTV.com, available at: www.ndtv.com/education/from-technological-queriesto-distress-calls-teachers-struggle-with-challenges-posed-by-lockdown-2208957

Pringle, J., Drummond, J., McLafferty, E. and Hendry, C. (2011), "Interpretative phenomenological analysis: a discussion and critique", Nurse Researcher, Vol. 18 No. 3.

Prottas, D.J., Cleaver, C.M. and Cooperstein, D. (2016), "Assessing faculty attitudes towards online instruction: a motivational approach", Online Journal of Distance Learning Administration, Vol. 19 No. 4.

Punit, I.S. and qz.com (2020). "For many of India's teachers, online classes amid lockdown have been an awful experience", Scroll.in, available at: https://scroll.in/article/961738/for-many-of-indias- 
teachers-online-classes-amid-lockdown-have-been-an-awful-experience (accessed 23 August 2020).

QS-ERA (2020), "COVID-19: a wake-up call for Indian internet service providers”, available at: www.igauge. in or www.igauge.in/news/2020/4/covid-19-a-wake-up-call-for-indian-internet-service-providers (accessed 23 August 2020).

Ryan, G.W. and Bernard, H.R. (2000), "Data management and analysis methods".

Saini, D. and Chaudhary, N.S. (2019), "What drives research in higher education? An Indian context", Journal of Applied Research in Higher Education.,

Sharma, A.K. (2020), “COVID-19: creating a paradigm shift in India's education system”, Economic Times Blog, available at: https://economictimes.indiatimes.com/blogs/et-commentary/covid-19creating-a-paradigm-shift-in-indias-education-system/ (accessed 31 July 2020).

Shea, P. (2007), "Bridges and barriers to teaching online college courses: a study of experienced online faculty in thirtysix colleges", Journal of Asynchronous Learning Networks, Vol. 11 No. 2, pp. 73-128.

Shenoy, V., Mahendra, S. and Vijay, N. (2020), "COVID 19 lockdown technology adaption, teaching, learning, students engagement and faculty experience", Mukt Shabd Journal, Vol. 9 No. 4, pp. 698-702.

Smith, J.A. (1996), "Beyond the divide between cognition and discourse: using interpretative phenomenological analysis in health psychology", Psychology and Health, Vol. 11 No. 2, pp. 261-271.

Smith, J.A. (2011), "Evaluating the contribution of interpretative phenomenological analysis", Health Psychology Review, Vol. 5 No. 1, pp. 9-27.

Smith, J.A. and Eatough, V. (2007), "Interpretative phenomenological analysis", in lyons, E. and Coyle, A., Analysing Qualitative Data in Psychology, pp. 35-64.

Smith, P.K, Smith, C., Osborn, R. and Samara, M. (2008), "A content analysis of school anti-bullying policies: progress and limitations”, Educational Psychology in Practice, Vol. 24 No. 1, pp. 1-12.

Smith, J.A. and Osborn, M. (2003), "Interpretative phenomenological analysis", Qualitative Psychology: A Practical Guide to Research Methods, pp. 53-80.

Stoffregen, J.D., Pawlowski, J.M., Ras, E., Tobias, E., Šcepanović, S., Fitzpatrick, D., Mehigan, T., Steffens, P., Przygoda, C., Schilling, P. and Friedrich, H. (2016), "Barriers to open e-learning in public administrations: a comparative case study of the European countries Luxembourg, Germany, Montenegro", Technological Forecasting and Social Change, Vol. 111, pp. 198-208.

Sutherland, S. (2014), "Team teaching: four barriers to native English speaking assistant teachers' ability to model native English in Japanese classrooms", Asian EFL Journal: Quarterly Journal, Vol. 16 No. 2, pp. 156-180.

Taylor, C.R. (2002), "E-learning: the second wave”, T and D, Vol. 56 No. 10, pp. 24-31.

UNESCO (2020), COVID-19 Educational Disruption and Response, UNESCO, available at: https://en.unesco. org/covid19/educationresponse (accessed 16 June 2020).

Verma, G. Campbell, T. Melville, W. and Park, B.Y. (2020), "Science teacher education in the times of the COVID-19 pandemic".

Yuen, A.H. and Ma, W.W. (2008), "Exploring teacher acceptance of e-learning technology", Asia-Pacific Journal of Teacher Education, Vol. 36 No. 3, pp. 229-243.

\footnotetext{
About the authors

Amit Joshi is a triple postgraduate in economics, commerce and English; he has completed the Master's diploma in international trade from Symbiosis, Pune. He has been awarded the degree of M. Phil. in economics and has a Doctorate degree in English. Currently, he is working as the Head of the Department at ICFAI Business School, ICFAI University Dehradun, Uttarakhand, India. His area of expertise includes English, business communication and life skills. He has more than 18 years of
} 
ITSE 18,2

teaching experience and has several research publications in various reputed journals to his credit. He has also authored the poetry book "Stimulus: From darkness to light (a collection of motivational poems)". He has presented research papers in several national and international conferences that include places such as Dusseldorf, Germany, Saint Petersburg, Russia and the University of Dubai. His research interests include communication strategy, the art of writing, disseminating knowledge, personal effectiveness, marginal productivity theory, trickledown effect and communication modeling. He has conducted many faculty development programs, student development programs and corporate training programs. His motto in life "if we are not a solution to a problem, then we are the problem".

Muddu Vinay is the Dean, IBS and Pro-Vice-Chancellor at the ICFAI University Dehradun, Uttarakhand, India. He has almost three decades of rich experience in the field of education, training, planning, management and consultancy. He is acknowledged not only for establishing institutions but also leading them to excellence in academics and research with his path-breaking initiatives. Dr Muddu Vinay has held several positions of eminence in professional bodies in the field of education both globally and in India. These include Chairman, Internal Quality Assessment Cell and Proctor, University of California, Berkeley Extension. He has spearheaded and pioneered various programmes in the field of higher education especially in postgraduate studies in collaboration with reputed schools in India, Australia, New Zealand, the UK, Singapore and Malaysia. He is the present expert peer committee member, National Board of Accreditation, Govt. of India, New Delhi. He has also been the expert member for various professional organizations that include Higher Education UK India Education and Research Initiative, World Bank and MHRD. He has been conferred with "Award of Excellence - Eminent Educationists" in the Indo-American summit 2016, MTC Global Award for Excellence 2013 in "Innovation in Teaching Pedagogy", "NESA Fellowship Award 2012" and "Leadership and Responsibility Award" by Presidency Group of Institutions, along with many other awards and accolades in his illustrious career. He has personally trained more than 30,000 individuals undertaking undergraduate, postgraduate studies as well as research scholars, university teachers and teaching staff. He is widely acclaimed for creating successful business models in the education sector without compromising on the ethical dimensions of teaching as a profession

Preeti Bhaskar is working as a Faculty at University of Technology and Applied Sciences (Ibra College of Technology, Ibra), Oman and Research Scholar at ICFAI Business School, ICFAI University, Dehradun, India. She possesses eight years of teaching experience in the area of Human Resource Management. She has done the MBA with a dual specialization in human resource management and marketing management from ICFAI Business School, Dehradun, Uttarakhand, India. Her research interest includes e-government, job performance, job satisfaction, sustainable development, continuing education and e-learning. She has published research papers in many reputed journals and presented research papers at various national and international conferences. She has also authored two books on "general management" and published case studies in Case Centre, the UK. She has also completed two minor research projects sponsored by the Symbiosis International University, Pune, Maharashtra. She is actively engaged in conducting student development programs and faculty development programs at various colleges and universities. Preeti Bhaskar is corresponding author and can be contacted at: preeti.bhaskar52@gmail.com

For instructions on how to order reprints of this article, please visit our website:

www.emeraldgrouppublishing.com/licensing/reprints.htm

Or contact us for further details: permissions@emeraldinsight.com 